\title{
Preparation of alkali-activated fly ash-based geopolymer and their application in the adsorption of copper (II) and zinc (II) ions
}

\author{
Lita Darmayanti ${ }^{1,2^{*}}$, Suprihanto Notodarmojo ${ }^{1}$, Enri Damanhuri ${ }^{1}$, Grandprix T. M. Kadja ${ }^{3}$, \\ and Rino R Mukti ${ }^{3}$ \\ ${ }^{1}$ Department of Environmental Engineering, Institut Teknologi Bandung, Bandung, Indonesia \\ ${ }^{2}$ Department of Civil Engineering, Universitas Riau, Pekanbaru, Indonesia \\ ${ }^{3}$ Division of Inorganic and Physical Chemistry, Institut Teknologi Bandung, Bandung, Indonesia
}

\begin{abstract}
Alkali activation of fly ash can a promising alternative of the system to improve adsorption capability of fly ash. In finding the best chemical composition of the activator solution, geopolymer has been synthesized using molar ratios of $\mathrm{Na}_{2} \mathrm{O} / \mathrm{SiO}_{2} 0.16,0.3$, and 0.5 (Gr1, Gr3, Gr5). The results indicated that the geopolymer synthesized with a ratio molar of $\mathrm{Na}_{2} \mathrm{O} / \mathrm{SiO}_{2} 0.3(\mathrm{Gr} 3)$ improved the adsorption properties of fly ash substantially. Gr3 was characterized by BET, XRD, and FTIR. The batch experiment was conducted at the different duration and initial concentrations. The equilibrium sorption data were fitted for the Langmuir and Freundlich equations. The maximum sorption capacities calculated from Langmuir isotherm was $54 \mathrm{mg} \mathrm{g}^{-1}$ and $47 \mathrm{mg} \mathrm{g}^{-1}$ for $\mathrm{Cu}$ (II) and $\mathrm{Zn}$ (II) respectively. The kinetic data reveal that the pseudo-second order model was appropriate for a description of the kinetic performance.
\end{abstract}

\section{Introduction}

Fly ash is a byproduct of electricity generation in a coal-fired power plant. It has been reported that fly ash could be useful for the removal of heavy metals, dyes, and organic matters from aqueous solution [1-3]. However, fly ash still shows lower adsorption capacity unless it is modified. Alkali activation is a technology that can enlarge utilization of fly ash. The alkali activation or geopolymerization is formed by mixing the fly ash with alkaline activators and then curing the paste at a certain temperature to result in a solid material [4]. Alkali activation transforms amorphous structures (partially or fully amorphous) from aluminosilicate material (natural or waste sources) into compact solids [5, 6]. Several studies showed that the main product of alkali activation of fly ash is an aluminosilicate gel $[4,7-8]$.

Physicochemical properties of adsorbents (surface area, pore distribution, and surface chemistry) are fundamental in assigning their performance for wastewater treatment. The chemical compositions of fly ash like its high percentage of silica, alumina, hematite and other characteristics of fly ash like particle size, porosity, and surface area are key

* Corresponding author: darmayanti2708@gmail.com 
parameters in establishing their adsorption capacity for a specific water pollutant [9]. These adsorbent characteristics can be tailored using alkali activation (geopolymerization). AlZboon [10] synthesis geopolymer with a $14 \mathrm{M}$ solution of $\mathrm{NaOH}$ could remove $\mathrm{Pb}$ from aqueous solution well. Solid state conversion of fly ash to an amorphous aluminosilicate (geopolymer) has been investigated and found that a higher temperature $\left(550^{\circ} \mathrm{C}\right)$ treatment resulted in the higher surface area and pore volume [11]. The use of $\mathrm{NaOH} 16 \mathrm{M}$ and $\mathrm{Na}_{2} \mathrm{SiO}_{3}$ as an alkaline activator to synthesis geopolymer has been done [12]. The geopolymer could adsorb $\mathrm{Cu}$ ion from aqueous solution effectively. The porous geopolymer was synthesized by alkaline activation of fly ash and iron ore tailing in alkali silicate solution and $\mathrm{H}_{2} \mathrm{O}_{2}$ as foaming agent [13]. The transformation of fly ash and iron ore tailing into foaming geopolymer induces the formation of porous structure promoting $\mathrm{Cu}$ (II) sorption. Both Langmuir and Freundlich models could explain the adsorption of $\mathrm{Cu}$ (II) on the porous geopolymer.

The alkali activation depends on many factors including the chemical and mineralogical composition of the raw materials, the kind of alkaline activators, their concentration and the ratio of main chemical activators such as $\mathrm{Na}_{2} \mathrm{O} / \mathrm{SiO}_{2}, \mathrm{SiO}_{2} / \mathrm{Al}_{2} \mathrm{O}_{3}$, and others $[14,15]$. In that sense, the main objective of this study was to gain a geopolymer with satisfactory sorption properties to remove heavy metal from alkali activated of fly ash and to study the geopolymer microstructure. The variable of the process was the $\mathrm{Na}_{2} \mathrm{O} / \mathrm{SiO}_{2}$ ratio.

\section{Materials and methods}

\subsection{Adsorbent}

The raw fly ash was collected from a coal-firing power plant of industrial textile in Bandung city, Indonesia. This material was sieved to a particle sizes less than $0.074 \mathrm{~mm}$ (sieve No. 200). The chemical composition of fly ash was determined by using Panalytical Epsilon 3 X-ray fluorescence spectrometry comprising of $\mathrm{SiO}_{2}(48.2 \%), \mathrm{Al}_{2} \mathrm{O}_{3}(35.4 \%)$, $\mathrm{CaO}(2.7 \%), \mathrm{Fe}_{2} \mathrm{O}_{3}(5.4 \%), \mathrm{MgO}(0.8 \%), \mathrm{SO}_{3}(3.2 \%)$, and others (4.3\%). The fly ash used was Class F (ASTM C-618) and had low calcium content. Alkaline activator consisted of $14 \mathrm{M}$ solution of $\mathrm{NaOH}$ prepared from $\mathrm{NaOH}$ pellets with $99 \%$ of purity and liquid sodium silicate $\left(29.4 \% \mathrm{SiO}_{2}, 14.7 \% \mathrm{Na}_{2} \mathrm{O}\right.$, and $\left.55.7 \% \mathrm{H}_{2} \mathrm{O}\right)$.

The geopolymers were synthesized by mixing fly ash with alkaline activator. The liquid/solid ratio was $0.6, \mathrm{SiO}_{2} / \mathrm{Al}_{2} \mathrm{O}_{3}$ ratio was 3 , and ratio of $\mathrm{Na}_{2} \mathrm{O} / \mathrm{SiO}_{2}$ were varied 0.16 , 0.3 , and 0.5 (named Gr1, Gr3, and Gr5 respectively). The activator solution was prepared at least 3 hours before adding the liquid to fly ash. After combining all the components, the mixture was mixed for 15-20 minutes and poured into polypropylene bottles. The bottles were closed to prevent moisture evaporation. The fresh pastes were heated at $85^{\circ} \mathrm{C}$ for 24 hours in an oven. Next, geopolymer was removed from the oven and stored at room temperature for three days. The activated fly ash bodies were washed with acetone to remove the excess alkaline activator and then crushed and sieved to obtain particle diameter less than $0.074 \mathrm{~mm}$ and then stored in a desiccator before use.

\subsection{Adsorbate}

$\mathrm{CuSO}_{4} .5 \mathrm{H}_{2} \mathrm{O}$ and $\mathrm{ZnSO}_{4} .7 \mathrm{H}_{2} \mathrm{O}$ were obtained in analytical grade (Merck Co.) and used without further purification. Distilled water was used throughout the experiment. 


\subsection{Characterization}

XRD patterns were studied by Bruker D8 Advance diffractometer with $\mathrm{Cu} \mathrm{K} \alpha$ radiation generated at $40 \mathrm{kV}$ and $35 \mathrm{~mA}$. Scattering patterns were collected in the $2 \theta$ range 5-500 with a step size of 0.020 . Nitrogen adsorption-desorption isotherms were obtained by using Quantachrome Novawin2 at the liquid nitrogen temperature of $-195.7^{\circ} \mathrm{C}$. Powder samples were outgassed at $300^{\circ} \mathrm{C}$ for three hours before analysis. The surface area calculation used the BET equation, and the FTIR analysis was conducted with Prestige 21 Shimadzu spectrometer. The $\mathrm{KBr}$ method was used to prepare the samples, which were scanned at a range of 4000 to $400 \mathrm{~cm}^{-1}$.

\subsection{Sorption experiment}

The sorption of copper and zinc ions were studied by shaking $0.1 \mathrm{~L}$ of $50 \mathrm{mg} / \mathrm{L} \mathrm{Cu}$ or $\mathrm{Zn}$ at a temperature of $25 \mathrm{C}$ with a constant amount of adsorbent $(0.15 \mathrm{~g})$ in batch reactors. The mixtures were shaken with a horizontal shaker at $150 \mathrm{rpm}$ for 60 minutes. The adsorption isotherm was studied after adding $0.15 \mathrm{~g}$ adsorbent into aqueous solutions containing the desired concentrations of $\mathrm{Cu}$ and $\mathrm{Zn}(5-60 \mathrm{mg} / \mathrm{l}), \mathrm{pH} 4$, and shaken for 60 minutes at room temperature. The kinetic studies were conducted at a concentration of $\mathrm{Cu}$ and $\mathrm{Zn} 50 \mathrm{mg} / \mathrm{l}$ with $0.15 \mathrm{~g}$ adsorbent for a predetermined time. The concentration of the metal ions in the filtered sample was determinate by atomic absorption spectrophotometer. The amount of metal retained on the adsorbent (q), was calculated by Eq. 1 as the difference between the amounts present in the initial metal solution and that remaining in the solution:

$$
q=\frac{(C o-C a) V}{m}
$$

where $\mathrm{Co}$ and $\mathrm{Ca}$ are the initial and equilibrium concentration of $\mathrm{Cu}(\mathrm{II})$ or $\mathrm{Zn}$ (II) solution $(\mathrm{mg} / \mathrm{l}), \mathrm{V}$ is the volume (l), and $\mathrm{m}$ is the weight ( $\mathrm{g}$ ) of adsorbent.

\section{Results and discussion}

\subsection{The optimization ratio of $\mathrm{Na}_{2} \mathrm{O} / \mathrm{SiO}_{2}$}

Geopolymerization is a chemical process that changes vitreous structures into wellcompacted composites [6]. This process needs a strongly alkaline medium to dissolve silica and alumina and to increase surface hydrolysis of the fly ash particles [16]. The medium can be acquired using simple or combined alkaline solutions. As geopolymerization starts from the hydrolysis of fly ash with $\mathrm{NaOH}$ and $\mathrm{Na}_{2} \mathrm{SiO}_{3}$, the ratio of $\mathrm{Na}_{2} \mathrm{O} / \mathrm{SiO}_{2}$ might affect the degree of hydrolysis which is related to successful adsorption. Increasing the $\mathrm{Na}_{2} \mathrm{O} / \mathrm{SiO}_{2}$ ratio affects geopolymerization and porosity [15]. Geopolymer has been prepared by mixing fly ash with the liquid/solid ratio was 0.6 , the $\mathrm{SiO}_{2} / \mathrm{Al}_{2} \mathrm{O}_{3}$ ratio was 3 , and the ratio of $\mathrm{Na}_{2} \mathrm{O} / \mathrm{SiO}_{2}$ varied between $0.16,0.3$, and 0.5 . The results of adsorption are shown in Fig. 1. It is clearly shown that the alkali-activated fly ash has a higher adsorption amount than raw fly ash as fly ash contains some impurities that can block the pores and retard the target solute from being adsorbed efficiently. Synthesized geopolymer has resulted in the shift of chemical system from the species with larger rings and complex structures to become monosilicates, have chains and become species with smaller rings [17-18]. This change can increase surface area and pore volume significantly making geopolymer have more sorption sites for metal ions. Increasing $\mathrm{Na}_{2} \mathrm{O} / \mathrm{SiO}_{2}$ ratio increases the total open porosity. However, the decrease of sodium silicate content decreases the available soluble $\mathrm{Si}$ atoms leading to 
an incomplete geopolymerization promoting the formation a microstructure characterized by macroporosity [15].

Fig. 1 shows a substantial increase in adsorption amount for $\mathrm{Cu}$ (II) and $\mathrm{Zn}$ (II) in all $\mathrm{Na}_{2} \mathrm{O} / \mathrm{SiO}_{2}$ ratio. However, the adsorption amounts increased and even slightly decreased at the higher $\mathrm{Na}_{2} \mathrm{O} / \mathrm{SiO}_{2}$ ratio, resulting from incomplete geopolymerization. Thus, the $\mathrm{Na}_{2} \mathrm{O} / \mathrm{SiO}_{2}$ ratio $0.3(\mathrm{Gr} 3)$ was selected as one of the optimized prepared condition.

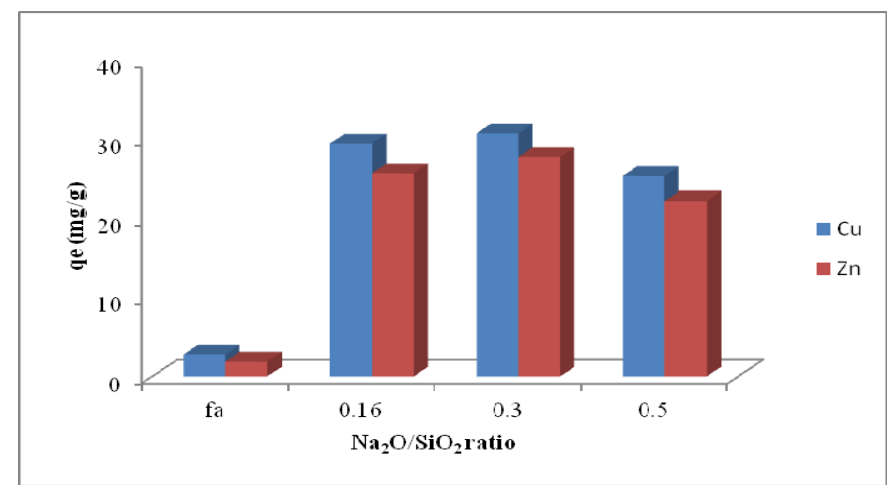

Fig. 1. Optimization of the $\mathrm{Na}_{2} \mathrm{O} / \mathrm{SiO}_{2}$ ratio for activation of fly ash.

\subsection{Characterization}

Characterization of adsorbent is essential to understand the property material. The BET surface areas and pore volumes of fly ash and activated fly ash were obtained from N2 adsorption as detailed in Table 1. It shows that the BET surface area and pore volume of Gr3 are much higher than raw fly ash. Hence, more active functional groups are exposed which can improve the adsorption capacity of Gr3.

Table 1. Textural properties of fly ash and activated fly ash.

\begin{tabular}{|c|c|c|}
\hline Sample & S BET $\left(\mathbf{m}^{2} / \mathbf{g}\right)$ & $\mathbf{V ~}\left(\mathbf{c m}^{3} / \mathbf{g}\right)$ \\
\hline Fly ash & 9.5 & 0.022 \\
\hline Gr3 & 29 & 0.134 \\
\hline
\end{tabular}

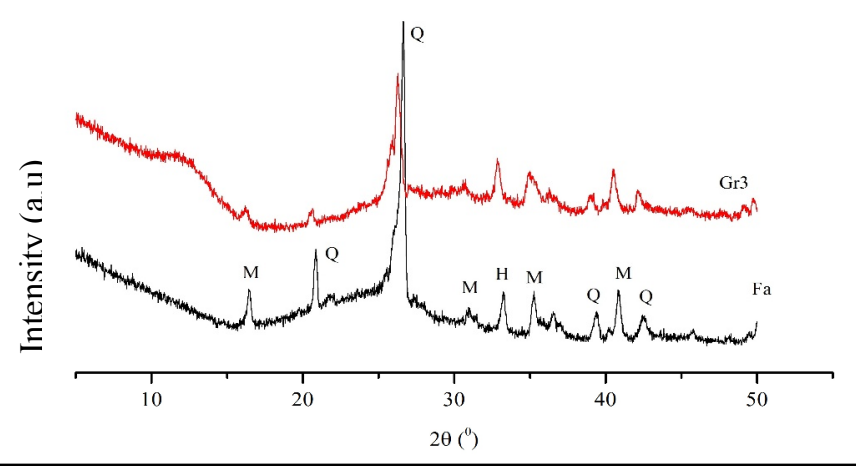

Fig. 2. X-ray diffraction of fly ash and Gr3.

Fly ash is an essentially amorphous material (halo recorded at $2 \theta=15-350$ ) that also contains a series of minority crystalline phases like quartz, mullite, and hematite. Activation 
of fly ash with alkali solutions change the diffraction pattern. It should be noted that the shift in the position of the halo attributed to the amorphous phase in the initial ash to slightly higher angular values $(2 \theta=20-400)$. The changes indicate the formation of an alkaline aluminosilicate gel (Fig. 2). The initial fly ash peaks of quartz, mullite, and hematite were also found in the samples of activated fly ash. However, these peaks tended to lose their intensity. This finding suggests that reactions disorganized the structure of the crystalline of the fly ash particles (quartz, mullite, and hematite) produced by the alkaline activator. No new crystalline phases were detected.

The infrared spectra raw fly ash and Gr3 are shown in Fig. 3. In raw fly ash, the broad peak at $3412 \mathrm{~cm}^{-1}$ and $1622 \mathrm{~cm}^{-1}$ were ascribed to the stretching and deformation vibrations of $\mathrm{OH}$ and $\mathrm{H}-\mathrm{O}-\mathrm{H}$ groups from the water molecules. While for $\mathrm{Gr} 3$, the broad bands are strong and these bands belong to the weakly bound water molecules which were adsorbed on the surface or trapped in the large cavities between the rings of geopolymer $[2,19]$. In the raw fly ash the strong peak at $1383 \mathrm{~cm}^{-1}$ was due to $\mathrm{CO}$ deformation vibration, and for $\mathrm{Gr} 3$ the weak peak at $1425 \mathrm{~cm}^{-1}$ was attributed to $\mathrm{CO}$ bending vibration. These bands show the sodium carbonate resulting from the carbonation of the $\mathrm{NaOH}$-rich geopolymer [20]. The bands at $1103 \mathrm{~cm}^{-1}$ correspond to the $\mathrm{Si}-\mathrm{O}$ asymmetric stretching in tetrahedra. The bands at $829 \mathrm{~cm}^{-1}$ and $567 \mathrm{~cm}^{-1}$ in the fly ash are indicated of mullite. In the geopolymer, the peak shift to $1078 \mathrm{~cm}^{-1}$ is ascribed to the product of geopolymer as a consequence of polycondensation with alternating $\mathrm{Si}-\mathrm{O}$ and $\mathrm{Al}-\mathrm{O}$ bonds [20]. The bands at $750 \mathrm{~cm}^{-1}$ and $458 \mathrm{~cm}^{-1}$ corresponded to $\mathrm{Si}-\mathrm{O}-\mathrm{Si} / \mathrm{Si}-\mathrm{O}-\mathrm{Al}$ and $\mathrm{Al}-\mathrm{O} / \mathrm{Si}-\mathrm{O}$ bending vibration respectively.

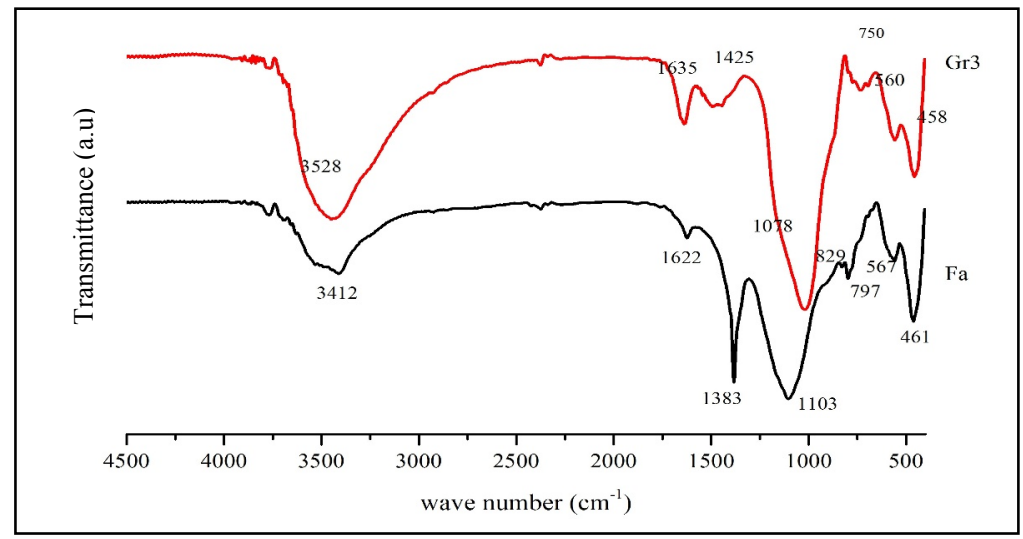

Fig. 3. FTIR spectra of fly ash and Gr3.

\subsection{Adsorption of $\mathrm{Cu}$ (II) and $\mathrm{Zn}$ (II)}

\subsection{Influence of initial concentration}

The batch sorption capacity as a function of initial concentrations of metals was studied at the range concentrations of 5-60 mg/l. Fig. 4 presents the percentage removal of synthesized geopolymer at various metals concentrations. The percentage removal depends on initial metals concentration. It was found that adsorption efficiency remains higher than $80 \%$ when the initial metal concentration was $60 \mathrm{mg} / \mathrm{l}$. These results show that the adsorption efficiencies of both metals decrease with an increase in the initial concentration. However, the amount of metals uptake per unit mass adsorbents, $\mathrm{q}(\mathrm{mg} / \mathrm{g})$, increased. The percentage removal decreases from $98 \%$ to $92 \%$ and from $97 \%$ to $87 \%$ in case of $\mathrm{Cu}$ (II) and $\mathrm{Zn}$ (II) respectively while q for $\mathrm{Cu}$ (II) and $\mathrm{Zn}$ (II) increases from 4 to $41 \mathrm{mg} / \mathrm{g}$ of 
adsorbent and 3 to $40 \mathrm{mg} / \mathrm{g}$ of adsorbent respectively. The increase of q could be attributed to greater mass driving force at a higher concentration which helps in overcoming mass transfer limitations [21].

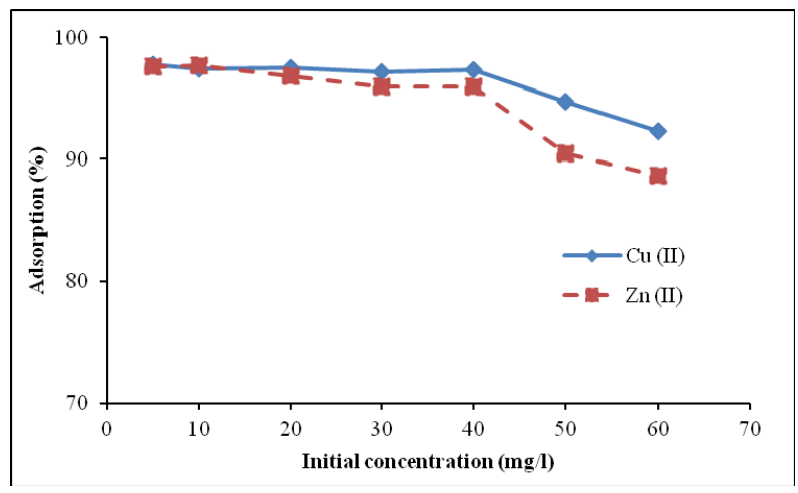

Fig. 4. Influence of initial metal concentrations on metals adsorption.

\subsubsection{Isotherm model}

The study of adsorption isotherm is vital in predicting the adsorption parameters. The different adsorption isotherms are characterized by its constants which that values suggest the surface properties and affinity of the sorbents to sorbates. Langmuir and Freundlich's models are commonly used in evaluating the adsorption process. The experimental data are fitted with these models. The Langmuir isotherm assumes that adsorption occurs at specific homogeneous sites within the sorbent and has found successful application in many analysis of monolayer adsorption [22]. The linear form of the Langmuir isotherm equation is given by the following equation:

$$
\frac{C e}{q e}=\frac{1}{K_{L} q_{m}}+\frac{C e}{q_{m}}
$$

where $\mathrm{Ce}$ is equilibrium concentration of metals in solution $(\mathrm{mg} / \mathrm{l})$, qe is the number of metals adsorbed onto adsorbents at equilibrium $(\mathrm{mg} / \mathrm{g}), \mathrm{KL}$ is the Langmuir equilibrium constant related to sorption energy, and qm is the maximum sorption capacity ( $\mathrm{mg} / \mathrm{g}$ ).

Langmuir isotherm may be reflected by a dimensionless parameter called separation factor. The dimensionless separation factor (RL) was calculated from the Langmuir isotherm using Eq. 3:

$$
R_{L}=\frac{1}{1+K_{L} C_{0}}
$$

where $\mathrm{KL}$ is the Langmuir adsorption constant and $\mathrm{C} 0$ is the initial concentration.

The Freundlich adsorption isotherm describes the equilibrium on the heterogeneous surface with sites having different adsorption energies, and it is multilayer adsorption [23]. The Freundlich isotherm can be represented [24] as:

$$
\ln q_{e}=\ln K_{F}+\frac{1}{n} \ln C_{e}
$$

where qe is the amount of $\mathrm{Cu}$ (II) ions adsorbed at equilibrium per unit weight of adsorbent $(\mathrm{mg} / \mathrm{g}), \mathrm{Ce}$ is the equilibrium concentration of $\mathrm{Cu}^{2+}$ ions in solution $(\mathrm{mg} / \mathrm{l})$, and $\mathrm{KF}$ and $\mathrm{n}$ 
are Freundlich constants corresponding to the strength of adsorption and the energetic heterogeneity of the adsorbent surface respectively [25].

The adsorption isotherms and values of Langmuir and Freundlich's constants obtained by the linear regression method are shown in Fig. 5 and the parameters are listed in Table 2.

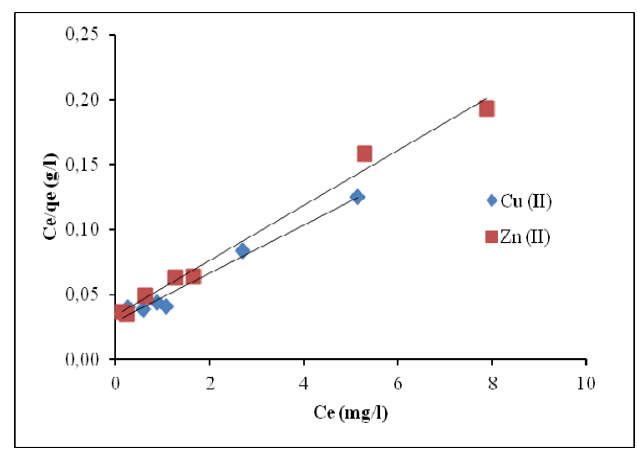

(a)

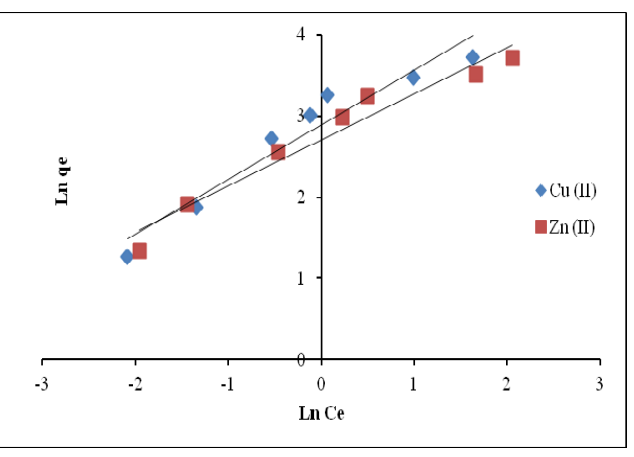

(b)

Fig. 5. Linerization of (a) Langmuir and (b) Freundlich isotherm models.

Table 2. The parameter of Langmuir and Freundlich isotherm models.

\begin{tabular}{|c|c|c|c|c|c|c|c|}
\hline \multirow{2}{*}{ Metals } & \multicolumn{4}{|c|}{ Langmuir } & \multicolumn{3}{c|}{ Freundlich } \\
\cline { 2 - 8 } & $\mathbf{q}_{\mathbf{m}}$ & $\mathbf{K}_{\mathbf{L}}$ & $\mathbf{R}^{\mathbf{2}}$ & $\mathbf{R}_{\mathbf{L}}$ & $\mathbf{K}_{\mathbf{F}}$ & $\mathbf{n}$ & $\mathbf{R}^{\mathbf{2}}$ \\
\hline $\mathrm{Cu}$ & 54.05 & 0.62 & 0.98 & $0.02-0.23$ & 18.08 & 1.49 & 0.93 \\
\hline $\mathrm{Zn}$ & 47.17 & 0.63 & 0.99 & $0.02-0.21$ & 14.98 & 1.77 & 0.95 \\
\hline
\end{tabular}

By comparing the correlation coefficient values (R2) described in Table 1, it was concluded that the experimental values fitted well into the Langmuir isotherm model compared with the Freundlich isotherm model for both metals. The high constants of KL represent the steep initial slope in the sorption model, indicating a desirable high affinity [26]. The RL parameter suggests the type of isotherm as, $\mathrm{RL}=0$ irreversible, $0<\mathrm{RL}<1$ favorable, RL $=1$ linear, and RL $>1$ unfavorable. The calculated RL values as listed in Table 1 lies between 0 and 1 indicating favorable adsorption for both metal ions.

The Freundlich isotherm is an empirical model applied for non-ideal sorption on heterogeneous surfaces as well as multilayer sorption [26]. The parameter of Freundlich isotherm, $\mathrm{KF}(\mathrm{mg} / \mathrm{g}$ ) and $\mathrm{n}$ (dimensionless) are the characteristics constants related to the strength of adsorption and the energetic heterogeneity of the adsorbent surface. The R2 values were 0.93 and 0.95 which indicate that Freundlich isotherm is acceptable to describe the adsorption of $\mathrm{Cu}$ and $\mathrm{Zn}$ on the geopolymer. The value of constant, $\mathrm{n}$ lies between $1<\mathrm{n}$ $<10$ which represent good favorable adsorption. Both Langmuir and Freundlich isotherm could elucidate the adsorption of $\mathrm{Cu}$ and $\mathrm{Zn}$ on the fly ash-based geopolymer although the values of $\mathrm{R}^{2}$ obtained by Freundlich isotherm are slightly lower than those obtained for Langmuir isotherm.

\subsubsection{Influence of contact time}

The influence of contact time on the adsorption of $\mathrm{Cu}$ and $\mathrm{Zn}$ was studied by varying the contact time from 1 to 120 minutes. The initial concentration of metals was kept fixed as 50 $\mathrm{mg} / \mathrm{l}$ while the amount of adsorbent mass added was $0.15 \mathrm{~g}$. The batch experiment was 
carried out at $\mathrm{pH} 4$ and room temperature. The results as shown in Fig. 6 which indicate that the adsorption of $\mathrm{Cu}$ is slightly higher than the adsorption of $\mathrm{Zn}$. The adsorption efficiencies increased with time passes and reached its maximum values, and after that remains constant. The adsorption metals are higher initially as there is a larger surface area of the adsorbent available for the adsorption of metals. The adsorption rates remain relatively high at the first 10 minutes then start to slow and reach a maximum value after 30 $\min$.

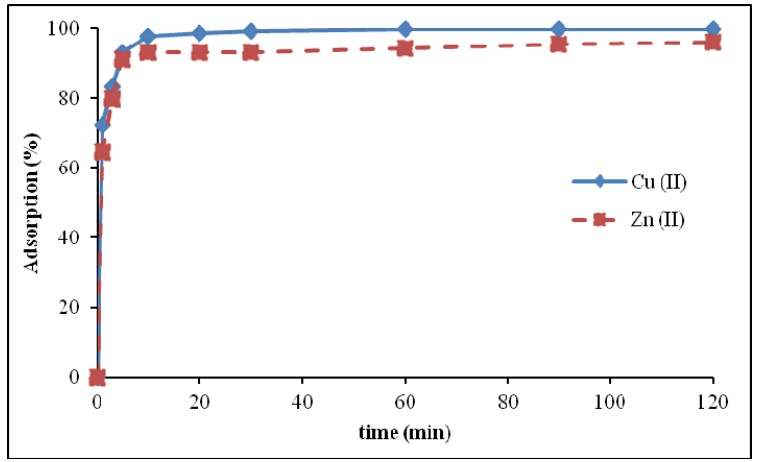

Fig. 6. Influence of contact time on metals adsorption.

\subsubsection{Kinetic model}

To investigate the mechanism of adsorption and its rate-controlling rate steps, pseudo-first order, pseudo-second-order, and intraparticle diffusion models were utilized and fitted with the experimental data. The Lagergren pseudo-first-order and Ho pseudo-second-order rate equations are given as [21]:

$$
\begin{gathered}
\log \left(q_{e}-q_{t}\right)=\log q_{e}-\frac{k_{1}}{2.303} t \\
\frac{t}{q_{t}}=\frac{1}{k_{2} q_{e}^{2}}+\frac{1}{q_{e}} t
\end{gathered}
$$

where qe and qt are the amounts of metals adsorbed $(\mathrm{mg} / \mathrm{g})$ at equilibrium and at time $\mathrm{t}$ (min) respectively, $\mathrm{k}_{1}\left(\mathrm{~min}^{-1}\right)$ and $\mathrm{k}_{2}(\mathrm{~g} / \mathrm{mg} . \mathrm{min})$ are the constants of pseudo-first-order rate constant and pseudo-second-order adsorption.

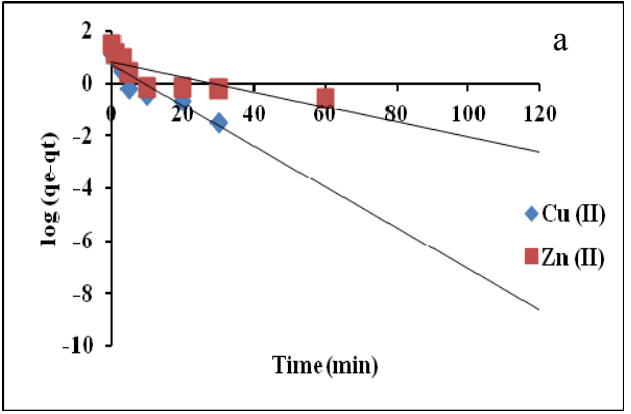

(a)

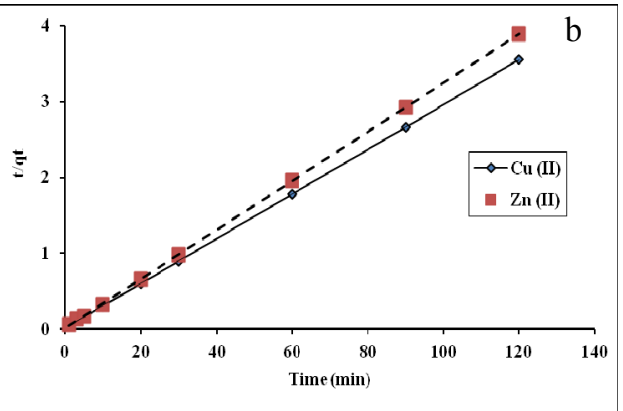

(b)

Fig. 7. (a) Pseudo-first order model and (b) pseudo-second-order model. 
The results are shown in Fig. 7 and Table 3. Results showed that the correlation coefficient $\left(\mathrm{R}^{2}\right)$ for the pseudo-second-order rate model is 0.99 for both metals which are higher than that of the pseudo-first-order rate model. In addition, adsorption capacity examined by pseudo-second-order rate model is closer to the experimental values. Therefore the pseudo-second-order rate model was selected to be the best fit model.

Table 3. Kinetic model constants and correlation coefficients.

\begin{tabular}{|l|c|c|c|}
\hline \multicolumn{1}{|c|}{ Model } & Parameter & $\mathbf{C u}$ & $\mathbf{Z n}$ \\
\hline Pseudo-first-order & $\mathrm{R}^{2}$ & 0.58 & 0.63 \\
\cline { 2 - 4 } & $\mathrm{qe}$ & 5.16 & 6.53 \\
\hline \multirow{2}{*}{$\begin{array}{l}\text { Pseudo-second- } \\
\text { order }\end{array}$} & $\mathrm{R}^{2}$ & 0.99 & 0.99 \\
\cline { 2 - 4 } & $\mathrm{K}_{2}\left(\mathrm{~g} / \mathrm{mg}^{2} \mathrm{~min}^{-1}\right)$ & 0.06 & 0.04 \\
\cline { 2 - 4 } & $\mathrm{qe}$ & 34.01 & 30.30 \\
\hline \multirow{3}{*}{$\begin{array}{l}\text { Intraparticle } \\
\text { diffusion }\end{array}$} & $\mathrm{R}^{2}$ & 0.97 & 0.97 \\
\cline { 2 - 4 } & $\mathrm{K}_{\mathrm{ld}}\left(\mathrm{mg} / \mathrm{g} \cdot \mathrm{min}^{-1 / 2}\right)$ & 8.30 & 8.51 \\
\cline { 2 - 4 } & $\mathrm{C}(\mathrm{mg} / \mathrm{g})$ & 11.82 & 7.84 \\
\cline { 2 - 4 } & $\mathrm{R}^{2}$ & 0.84 & 0.95 \\
\cline { 2 - 4 } & $\mathrm{K}_{2 \mathrm{~d}}\left(\mathrm{mg} / \mathrm{g} \cdot \mathrm{min}^{-1 / 2}\right)$ & 0.08 & 0.13 \\
\hline
\end{tabular}

The Weber and Morris intraparticle diffusion equation can be written as follow [27]:

$$
q_{t}=k_{i d} t^{1 / 2}+C
$$

where $\mathrm{ki}\left(\mathrm{mg} / \mathrm{g} \cdot \mathrm{min}^{-1 / 2}\right)$ is the rate constant of stage $\mathrm{i}(\mathrm{i}=1,2,3)$, and $\mathrm{C}$ is an indicator to express the boundary layer thickness [28]. The plot of qt versus $\mathrm{t}^{1 / 2}$ is shown in Fig. 8, and the kid calculated from the plot are listed in Table 2.

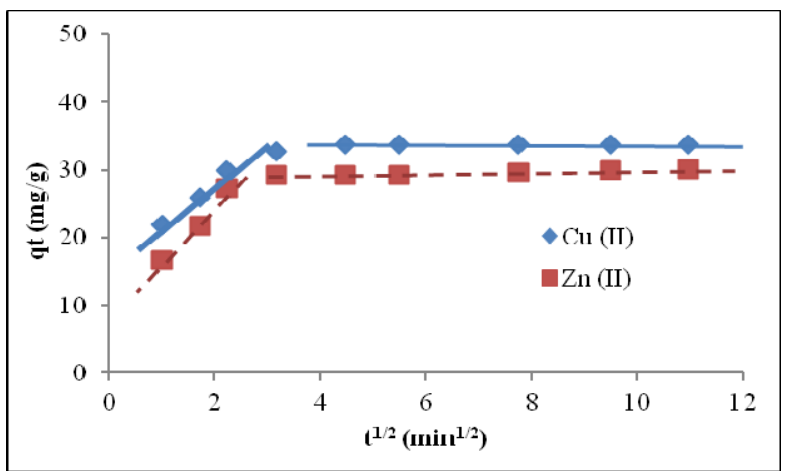

Fig. 8. Weber and Morris intraparticle diffusion model plots.

Fig. 8 shows that the data of $\mathrm{Cu}$ and $\mathrm{Zn}$ adsorption exhibits multilinear plots and plots do not pass through the origin. It indicates that sorption of adsorbates $\mathrm{Cu}$ (II) and $\mathrm{Zn}$ (II) on the adsorbent occur in two steps. In the first step, the sorption of adsorbates occurs on an 
external surface of adsorbent (film diffusion) while in the second step, the adsorbates penetrate through the pores of the adsorbent (intraparticle diffusion). From Table 2 the order of diffusion rate constant value is $\mathrm{k}_{1 \mathrm{~d}}>\mathrm{k}_{2 \mathrm{~d}}$ for both metals. The $\mathrm{C}$ value for $\mathrm{Cu}$ is greater than that of $\mathrm{Zn}$ which indicates the greater effect of the boundary layer on the adsorption process of $\mathrm{Cu}$. In the intraparticle diffusion model, the coefficient values $\left(\mathrm{R}^{2}\right)$ are nearer to that of the pseudo-second-order kinetic model, which indicate that the intraparticle is not only the rate controlling step. It may be deduced that the film diffusion and intraparticle diffusion both function parallel [26].

\subsubsection{Comparison with other adsorbents}

Table 4. Adsorption capacities for copper and zinc ions of various adsorbents.

\begin{tabular}{|c|c|c|c|}
\hline Metal & Adsorbent & $\begin{array}{c}\text { Adsorption } \\
\text { capacity }(\mathrm{mg} / \mathrm{g})\end{array}$ & Ref \\
\hline \multirow{6}{*}{$\mathrm{Cu}$} & $\mathrm{Fe}_{3} \mathrm{O}_{4}$ montmorillonite nanocomposite & 70.0 & [28] \\
\hline & $\begin{array}{l}\text { Fly ash and iron ore tailing based } \\
\text { geopolymer }\end{array}$ & 65.8 & [13] \\
\hline & Fly ash based geopolymer & 54.1 & This work \\
\hline & Coal fly ash pellets & 52.0 & [29] \\
\hline & Cassava peel activated carbon & 49.3 & [30] \\
\hline & Egyptyan kaolin based zeolite & 43.8 & [31] \\
\hline \multirow{6}{*}{$\mathrm{Cu}$} & Chemically $\left(\mathrm{ZnCl}_{2}\right)$ activated carbon residu & 23.1 & [32] \\
\hline & Olyster shell powder & 20.9 & {$[1]$} \\
\hline & Na bentonite & 17.9 & [33] \\
\hline & Chemically treatment fly ash & 15.2 & [27] \\
\hline & Modified mangrove bark & 6.9 & [34] \\
\hline & Bagasse fly ash & 2.3 & [35] \\
\hline \multirow{7}{*}{$\mathrm{Zn}$} & Cancrinite type zeolite (ZFA) & 75.5 & [37] \\
\hline & Fly ash based geopolymer & 47.1 & This work \\
\hline & Egyptyan kaolin based zeolite & 41.1 & [31] \\
\hline & Sesame straw biochar & 34.0 & [38] \\
\hline & Carrot residues & 29.6 & [39] \\
\hline & Hardwood ans corn straw & 11.0 & [40] \\
\hline & Al-Si-O bearing mineral & 3.7 & [41] \\
\hline
\end{tabular}


Comparison of adsorption capacity of other adsorbents for $\mathrm{Cu}$ and $\mathrm{Zn}$ has been made between fly ash-based geopolymer and previously reported adsorbent. The results are listed in Table 4. It can be seen that results obtained in this study are higher than the results obtained by other investigations. However, it was hard to conclude the comparison because of the different adsorbents, treatment methods, and conditions of sorption. However, a general overview showed that fly ash based geopolymer could compete with other adsorbents.

\section{Conclusions}

A fly ash-based-geopolymer was successfully prepared by a simple alkaline activation with $\mathrm{NaOH}+\mathrm{Na}_{2} \mathrm{SiO}_{3}$, and it was applied to adsorption of $\mathrm{Cu}$ and $\mathrm{Zn}$ from aqueous solutions. The optimal conditions for preparation of fly ash-based-geopolymer were: ratio $\mathrm{Na}_{2} \mathrm{O} / \mathrm{SiO}_{2}$ 0.3 , ratio $\mathrm{SiO}_{2} / \mathrm{Al}_{2} \mathrm{O}_{3} 3$, ratio water/solid 0.6 , and temperature of activation $85^{\circ} \mathrm{C}$. BET analysis demonstrates that fly ash-based-geopolymer is porous and its surface area is three times larger than raw fly ash. Improvement of the structural properties of the fly ash-basedgeopolymer and percentage of adsorption indicates the excellence of fly ash-basedgeopolymer for removing heavy metals ion from wastewaters. The adsorption isotherm can be well fitted by the Langmuir model with adsorption capacity found to be $54.05 \mathrm{mg} / \mathrm{g}$ and $47.17 \mathrm{mg} / \mathrm{g}$ for $\mathrm{Cu}$ and $\mathrm{Zn}$ respectively. The results of kinetic data were revealed that the adsorption kinetic data is fitted well with the pseudo-second-order model. The sorption phenomenon of metals indicates the first external film diffusion and then undergoes intraparticle diffusion process.

This study was financially supported by the Directorate of Research and Community Service, Ministry of Research, Technology and Higher Education, Indonesia (Grant number 271/UN.19.5.1.3/PP/2018).

\section{References}

1. T.C. Hsu, C.C. Yu, C.M. Yeh, Fuel 87 (2008)

2. M. Visa, L. Isaac, A. Duta, Appl. Surface Sci. 263 (2012)

3. L. Li, S. Wang, Z. Zhu, J. of Colloid and Interface Sci. 300 (2006)

4. M. Criado, A. Fernandez-Jimenez, A. Palomo. Micropor. Mesopor. Mat. 106 (2007)

5. A. Palomo, M.W. Grutzeck, M.T. Blanco, Chem. Con. Res. 29 (1999)

6. A.S de Vargas, DCCD. Molin, ACF. Vilela, F.J da Silva, B. Pavão, H. Veit, Cem. Con. Composites 33 (2011)

7. A. Fernández-Jiménez, A. Palomo, Cem. Con. Res. 35 (2005)

8. P. Duxson, A. Fernandez-Jimenez, J.L. Provis, G.C. Lukey, A. Palomo, JSJ. van Deventer, J. Mat. Sci. 42 (2007)

9. M. Ahmaruzzaman, M. Coll. Interface Sci. 166 (2011)

10. K. Al-Zboon, M. Al-Harahsheh, F. Hani, J. of Hazardous Mat. 188 (2011)

11. S. Wang, L. Li, ZH. Zhu. J. of Hazardous Mat. B139 (2007)

12. M.N. Mužek, S. Svilović, J. Zelić, Desalination and Water Treatment, 52 (13-15) (2013)

13. P. Duan, C. Yan, W. Zhou, D. Ren, Ceramics International, 142 (2016)

14. J. Temuujin, RP. Williams, Av. Riessen, J. of Materials Process. Tech. 209 (2009) 
15. M.C. Bignozzi, S. Manzi, M. Elia, WDA. Rickard, A. van Riessen, Con. Build. Mat. 69 (2014)

16. JGS. van Jaarsveld, JSJ. van Deventer, L. Lorenzeni, Minerals Eng. 10, 7 (1997)

17. D. Panias, I.P. Giannopoulou, T. Perraki, Coll. and Surfaces A: Physicochemichal Eng. Aspects 301 (2007)

18. A.D. Hounsi, G. Lecomte-Nana, G. Djétéli, P. Blanchart, D. Alowanou, P. Kpelou, K. Napo, G. Tchangbédji, Ceramics Int. 40 (2014)

19. Y. Liu, C. Yan, Z. Zhang, H. Wang, S. Zhou, W. Zhou, Fuel 185 (2016)

20. S. Andini, R. Cioffi, F. Colangelo, T. Grieco, F. Montagnaro, L. Santoro, Waste Man. 28 (2008)

21. B. Agarwal, C. Balomajumder, P.K. Thakur, Chem. Eng. J. 228 (2013)

22. I. Langmuir, J. Am. Chem. Soc. 38 (1916)

23. F. Wang, Y. Pan, P. Cai, T. Guo, H. Xiao, Biores. Tech. 241 (2017)

24. HMF Freundlich, J. Phys. Chem. 57 (1908)

25. E. Worch, Adsorption technology in water treatment (Walter de Gruyter, Berlin/Boston, 2012)

26. B.A Shah, C.B. Mistry, A.V. Shah, Chem. Eng. J. 220 (2013)

27. E. Soc`o, J. Kalembkiewicz, Croatia Chemical Acta 88, 3 (2015)

28. K. Kalantari, M.B. Ahmad, HRF. Masoumi, K. Shameli, M. Basri, R. Khandanlou, J. of the Taiwan Inst. of Chemical Eng. 49 (2015)

29. A. Papandreou, C.J. Stournaras, D. Panias, J. of Hazardous Mat. 148 (2007)

30. J.C. Moreno-Pirajan, L. Giraldo, J. Anal. Appl. Pyrol. 87 (2010)

31. H.S. Ibrahim, T.S. Jamil, E.Z. Hegazy, J. of Hazardous Mat. 182 (2010)

32. H. Runtti, S. Tuomikoski, T. Kangas, U. Lassi, T. Kuokkanen, J. Rämö, J. of Water Process Eng. 4 (2014)

33. Z. Liu, S. Zhou, Process Saf. Environ. Prot. 88 (2010)

34. C.A. Rozaini, K. Jain, C.W. Oo, K.W. Tan, L.S. Tan, A. Azraa, K.S. Tong, Int. Journal of Chem. Eng. and Applications 1, 1 (2010)

35. V.K. Gupta, I. Ali, Separation and Purification Tech. 18 (2000)

36. H.S. Ibrahim, T.S. Jamil, E.Z. Hegazy, J. of Hazardous Mat. 182 (2010)

37. W. Qiu, Y. Zheng, Chem. Eng. J. 145 (2009)

38. J.H. Park, Y.S. Ok, S.H. Kim, J.S. Cho, J.S. Heo, R.D. Delaune, D.C. Seo, Chemosphere 142 (2016)

39. B. Nasernejad, T.E. Zadeh, B.B. Pour, M.E. Bygi, A. Zamani, Process Biochemistry 40 (2005)

40. X. Chen, G. Chen, L. Chen, Y. Chen, J. Lehmann, M.B. McBride, A.G. Hay, Bioresource Tech. 102 (2011)

41. S.S. Rath, S. Singh, D.S. Rao, B.B. Nayak, B.K. Mishra, Separation and Purification Tech. 186 (2017) 